\title{
DIE TENTMAKERBEDIENING
}

\section{J.J. Kritzinger}

Tien jaar gelede was die konsep van 'n tentmakerbediening nog bykans onbekend in Ned Geref Kerkkringe. Vandag is daar nie alleen tientalle leraars wat hulleself as "tentmakers" beskryf nie, madr is die saak nog fel omstrede. As een van dié wat die ontwikkelinge die afgelope 10 jaar met groot belangstelling dopgehou en begelei het, en tans ook as ' $n$ "tentmaker" kan deurgaan, is dit dalk tyd om 'n poging aan te wend om sommige misverstande op te klaar en die verkynsel in sy breë verband te beskryf." Ek persoonlik is daarvan oortuig dat enige bedieningstruktuur wat in die toekoms beide Bybels gefundeerd (Gereformeerd) en prakties toepaslik wil wees, plek sal moet inruim vir ' $n$ vorm van tentmakerbediening. Ek sien dit dus beslis nie as 'n teken van verval of iets wat ten alle koste teengewerk moet word nie. Maar aan die ander kant sien ek dit ook nie as die finale oplossing vir alle bedieningsprobleme nie - inteendeel, ek is maar te bewus van die probleme verbonde daaraan. Hierdie probleme is nie altyd inherent aan hierdie vorm van die bediening nie, maar spruit dikwels voort uit die onvolkomenheid van die bekleërs van die bediening en die gebreke in die samelewing.

\section{SOORTE TENTMAKERS}

Heelwat van die misverstande hang saam met die feit dat die "tentmakerbediening" 'n sambreelterm geword het vir verskeie verskyningsvorme. Die een gemeenskaplike faktor wat iemand in die volksmond ' $n$ tentmaker maak, is dat hy homself geheel of gedeeltelik buite die kerk om onderhou en sodoende nie al sy tyd aan die gemeente of spesifieke bedieningstaak wy nie.

Drie indelingsbeginse/s kan gebruik word om die tentmakerverskynsel te klassifiseer: die bron van finansiële onderhoud, kerkregtelike status van die persoon, en die terrein van diens.

\section{Volgens bron van onderhoud:}

(a) Sommige verdien hulle volledige onderhoud buite die gemeente. Uiteraard beklee sulkes ' $n$ voltydse betrekking en bestee "vrye" tyd aan die gemeente. Gewoonlik is dié betrekking sekulêr (onderwys, besigheid, klerk, ens.), maar dit kan natuurlik ook 'n ander kerklike 
betrekking wees (my eie voorbeeld, teologiese dosente in die NH Kerk, ens.). Maar ook pensionarisse kan op hierdie manier dien.

(b) Ander verdeel hulle tyd tussen die gemeente en ' $n$ ander bedryf en verdien dus uiteraard by geen van beide ' $n$ voile salaris nie. Die gemeente dra 'n gedeelte by en in die res van die tyd word probeer om ook 'n inkomste te verdien (besigheid, uurwerk, ens.).

(c) Nog ander werk voltyds in die gemeente en ontvang die voile vergoeding wat die gemeente kan aanbied, maar aangesien dit onvoldoende is, word die leraar toegelaat om 'n byverdienste te vind (in die onderwys, besigheid, of eie bedryf). Die Amerikaners noem dit "moonlighting."

Waar (a) die eintlike tentmaker is, kan (b) ook baie goed werk - mits daar ' $n$ behoorlike ooreenkoms in verband met tydsbesteding bestaan. Die kategorie (c) is egter alles behalwe bevredigend en is hoofsaaklik verantwoordelik vir die probleme wat ondervind word - en ongelukkig is dit die algemeenste vorm in veral die NG Kerk in Afrika.

2. Klassifikasie volgens "status" is ook moontlik. As aanvaar word dat die tentmaker sy onderhoud buite die gemeente verdien, kan die volgende vorme onderskei word:

(a) Die geordende leraar wat vroeër voltyds in die gemeente gewerk het en deur die gemeente onderhou is, maar nou nie meer nie. Hy dien egter nog steeds as ' $n$ leraar van die gemeente met ' $n$ beperkte opdrag. (Vgl. die leraars van die Reformed Church in Africa).

(b) Die geordende leraar wat nog nooit deur die gemeente onderhou is nie maar nog altyd homself onderhou het - en tog as leraar met beperkte opdrag in die gemeente bevestig is (my eie voorbeeld).

(c) Die teoloog (of nie-teoloog) wat op deeltydse grondslag in die gemeente dien, maar nie as leraar bevestig is nie. (Voorbeelde hiervan is verskeie teologiese dosente wat "pastorale hulp" in gemeentes verleen.)

Die kernbegrip hier is telkens die "beperkte opdrag." Alhoewel (a) en (c) die meer bekende vorme in Gereformeerde kringe is, is (b) die vorm wat deur die loop van die geskiedenis van die kerk en wêreldwyd die bekendste en algemeenste is. 
3. Ons kan ook onderskei op grond van die diensterrein van die persoon.

(a) Daar is dié tentmakers wat die gemeente bedien - as herder, as leraar, of in ' $n$ ander hoedanigheid.

(b) Daar is ook dié tentmakers wat primêr sendelinge is. Talle situasies in die wêreld sluit die moontlikheid uit dat iemand openlik as sendeling daar kan gaan werk. In sekere Moslem- of Marxistiese lande $k$ an iemand alleen toegang kry as ' $n$ kundigheid aangebied word waaraan daar ' $n$ tekort is. ${ }^{2}$ '

\section{WAAROM VANDAG SO OMSTREDE?}

Aan die een kant is daar groot entoesiasme vir die saak. Die kringe waarin die entoesiasme voorkom, en die vreemdheid van die gedagte, laat ander groepe weer sterk weerstand bied.

1. Dit is veral in die meer konserwatiewe, amptelike kerklike kringe waarvandaan die teenstand kom.

(a) Die argumente is in die eerste plek kerkregtelik van aard. Die NG kerk se Algemene Sinode het in 1982 daarop gewys

"... dat predikante en gelegitimeerde proponente wat werk aanvaar wat nie deur artikel 11 van die Kerkorde gedek word nie, ingevolge paragraaf 6.1 van die Reglement vir die Reëling van die Opleiding en Legitimasie van Evangeliedienaars, hulle status verbeur."

Die betrokke artikel 11 van die Kerkorde sê o.a. dat 'n predikant alleen sy gemeente mag verlaat om ' $n$ ander betrekking te aanvaar en nogtans status behou

"... indien die betrekking wat hy aanvaar, 'n geestelike karakter dra en wat met die verkondiging van die Woord in regstreekse verband staan en ten bate van die Nederduitse Gereformeerde Kerk geag word."

Die kerkregtelike hek word dus taamlik dig toegemaak, alhoewel $P$. Coertzen dit versigtig stel: ${ }^{3 \prime}$ 
"Dit is nie geheel en al onmoontlik dat ons 'n tentmakerbediening in die Ned. Geref. Kerk sou kon kry nie."

(b) Tweedens word sekere beginsels beklemtoon. Die NG Sendingkerk het by sy Sinode in 1982 wel die deur effens wyer oopgemaak, maar daarvoor probeer "opmaak" deur 'n paar baie sterk (en myns insiens aanvegbare stellings te maak:

“3.8.1 Die sinode handhaaf die voltydse bediening van die Evangelie as die normale weg waarlangs die Evangeliedienaar al sy tyd en kragte aan dié taak sal wy.

“3.8.2 ... dat dit slegs in buitengewone omstandighede as legitiem beskou moet word.

“3.8.3 Die enigste motief ... moet altyd wees die finansiële onvermoë van die gemeente...

“3.8.4 ... ernstige gevaar van 'n verskraling van die bediening kan meebring en dus nooit as die normale gang van sake beskou mag word nie ..."

Terwyl niemand meer ' $n$ saak daarvoor probeer uitmaak dat die tentmakerbediening Bybels gesproke ' $n$ onmoontlikheid is nie, word die gebruik van voltydse betaalde werkkragte egter so beklemtoon dat dit ander moontlikhede feitlik uitsluit.

(c) Derdens word daar op grond van praktiese probleme weerstand gebied. Dit kan net nie werk nie, word gesê. Die gemeentebediening is te veeleisend; die lewe "daarbuite" sal die bedienaar heeltemaal opeis; die amptelike Kerk behou te min beheer oor die bedienaar; wanneer gaan kerklike vergaderings nou gehou word?; wat van die pensioen?; kan so een nog beroep word?; is daar nie te veel kanse vir misbruike nie?

Die besluite van die NG Kerk in Afrika en Reformed Church in Africa, wat albei die tentmakerbediening as ' $n$ moontlikheid aanvaar het, is dan ook hoofsaaklik op hierdie praktiese reëlings gerig. Daarom word skriftelike ooreenkomste verlang, die betrokke ring(e) moet kontroleer, dit moet jaarliks hersien word, ens.

Daar is inderdaad praktiese probleme. Daar is ongelukkig ook reeds voorbeelde waar die gemeentes uiteindelik die slegste daarvan afkom. Hierdie voorbeelde word met groot vrug deur die teenstanders aangewend met 'n "ek het jul mos gesê!" 
(d) Dit openbaar egter die waarheid dat die weerstand teen die tentmakerbediening meestal emosioneei en irrasioneel is. Aan die een kant is dit ' $n$ vreemde, nuwe (vir die NG Kerke) saak. Mense wat gewoond geraak het aan 'n sekere orde wil dit nie graag verander nie.

Verder bring dit 'n gevoel van bedreiging na vore. Gaan ek ook daartoe gedwing word? Sê nou dit werk so goed, sal die gemeente nog gewillig wees om vir my onderhoud te sorg? Ek het nie ander kwalifikasies nie ... Basies word die agente van die vernuwing egter wantrou. Wat is ten slotte die mense se motiewe? Wil hulle nie maar loskom uit die kontrole wat daar oor hulle van kerkweë is nie? Hulle wil net hulleself verryk. Dit is politiek: hulle wil net nie die NG Kerk se geld aanvaar nie. Hulle wil die kerk op sy knieë dwing!

2. Die entoesiasme en uitdagendheid van die voorstanders trek ook aandag. Dit is meestai die jonger geslag, minder vas aan die tradisies en met meer aanvoeling vir eksperimentering, wat voorspraak vir die tentmakerbediening maak. Die Kerke in die NG Kerkfamilie wat dit tot dusver goedgekeur het, is die jongstes van die familie, nl. die NG Kerk in Afrika en die Reformed Church in Africa.

Die beweegredes wat tot die aantreklikheid van die tentmaker bydra, kan hoofsaaklik onder twee hoofde tuisgebring word.

(a) Aan die een kant word die finansiële nood van die Kerke as aanleiding aangegee. Die feit dat die gemeentes van die armer gemeenskappe net glad nie hulle voltydse leraars kan onderhou nie, lei tot veel ongelukkigheid. Nie alleen moet die werkkragte eksistensieel daaronder ly nie - en dit nadat hulle dikwels met groot opoffering hulleself akademies bekwaam het - maar die gevolg is ook dat hierdie gemeentes gevaarlik van buite gesubsidieer en aan die gang gehou moet word. Hierdie afhanklikheid het ernstige gevolge vir die funksionering van die betrokke gemeentes.

Dit is waarom die tentmakerbediening veral in die Derde Wêreld so algemeen is. Kerke wat geen finansiële hulp van elders ontvang nie, het meestai geen ander patroon geken nie. Die mees bekende voorbeelde is die snel groeiende Pinksterkerke in LatynsAmerika en die Onafhanklike Swart Kerke van Suid-Afrika. Hierdie groepe het nie die duur strukture van die Westerse Kerke geërf nie, maar kon hulle eie spontane patrone vorm.

(b) In die Weste is dit veral die missionere nood wat mense na hierdie 
alternatief dryf. Toenemend word besef watter afstand daar tussen die wêreld van die predikant in die gemeente en die wêreld van die lidmate is. Hoeveel minder kan die gaping na die buite-kerklikes ooit oorbrug word behalwe as iemand uit sy wêreld vertrek en die ander sekulêre wêreld van die mense betree? Sedert die sg. "worker priests" van Frankryk in die vyftigerjare as arbeiders in die fabrieke gaan werk het, is verskeie ander eksperimente deurgevoer. Die getuienis was deurgaans dat, hoewel dit nie maklik is nie, dit in die moderne wêreld kosbare kommunikasiemoontlikhede bied.

Hierdie beweegrede sou net so veel (indien nie nog in groter mate nie) vir die Derde Wêreld se Kerke geld, maar die stryd om den brode kry hier gewoonlik voorrang.

Wat egter waar is, is dat hierdie missionêre betrokkenheid die kerk soms in ongemaklike situasies laat beland. Die Franse werkers-priesters het bv. hulle werk so goed gedoen dat hulle in die vakbondwese betrokke geraak het op so 'n skaal dat die Katolieke hierargie hulle uiteindelik uit die fabrieke onttrek het. Net so speel politieke en radikale argumente ook 'n $\mathrm{rol}$ in die begeerte om finansieel onafhanklik te funksioneer. Die vraag is egter of dit reg is om weens hierdie rede nie bereid te wees om die uitdagings te aanvaar nie.

\section{IS DIE SAAK IN ORDE?}

\section{Bybelse beginsels vir bedieningspatrone}

Veral drie beginsels oor bedieningstrukture kom na vore wanneer ons die Bybelse gegewens bestudeer. ${ }^{4}$

(a) Die balans tussen die algemene en die besondere bediening

Die Reformasie se groot klem op die priesterskap van elke gelowige is nie uit die lug gegryp nie. I Pet 2:9 praat van die kerk as 'n "volk van priesters." Ons is ' $n$ volk sonder spesiale priesters - almal het priesterfunksies. Nogtans moet daarmee geensins die indruk geskep word dat daar nie ook ' $n$ besondere bediening is nie. Om maar een Skrifgedeelte te noem: Ef 4:11 praat van 'n sekere "sommige", besondere mense wat as gawes aan die gemeente gegee is. Dit is duidelik dat dit op die blywende ampte slaan. ${ }^{51}$ 
Die telkens gebruikte beeld van die kerk as "die liggaam van Christus" (I Kor 12-14, Rom 12, Ef 4) maak onmiskenbaar duidelik dat daar altyd ' $n$ groot verskeidenheid van gawes en bedieninge tot opbou van die liggaam sal wees. Die liggaam mag nie teen homself verdeel wees nie, maar daar moet ' $n$ harmoniese balans en samewerking wees. Die groot afstand tussen algemene en besondere amp moet verminder word. ${ }^{61}$

(b) Geen bepaalde bedieningstruktuur is deur die Nuwe Testament normatief gemaak nie

Daar kan geen twyfel wees dat daar ' $n$ verskeidenheid bedieningsvorme in die Nuwe Testamentiese tyd langs mekaar bestaan het nie. Bolkestein ${ }^{71}$ wys op die groot verskil in die beeld van die gemeente-organisasie wat Johannes in sy geskrifte laat deurskemer en dié van die Pastorale Briewe. By Johannes heers die vryheid maar die Gees lei mense in die wáárheid. In die Pastorale Briewe staan die orde voorop. Teen die gnostiek is dit die amp, die outoriteit wat na vore moet tree - al word die geestesgawes ook veronderstel. Nêrens word die gemeentelid onmondig of die amp priesterlik nie. Die Pastorale Briewe gee blyke van organisasie in die stryd teen die dwaalleer. Johannes korrigeer weer die gevaar van 'n sakrale kerk. Die twee hoort albei daar. Hulle het mekaar nodig. Aldus Bolkenstein.

Ook Paulus se briewe gee aanduiding van ' $n$ wye verskeidenheid. Vergelyk weer eens die soort geordendheid van die gemeentes van die Pastorale Briewe met dié van Korinthe. Daar was in elke gemeente een of ander soort vorm, maar dit het van gemeente tot gemeente verskil na gelang die omstandighede verskil het - en dit het nie die eenheid in gevaar gestel nie.

Daar is nie afdoende bewys dat die verskille verklaar kan word deur ' $n$ evolusionêre ontwikkeling in die rigting van ' $n$ meer outoritêre gesagstruktuur nie. Dit lyk asof elke situasie sy eie uitdagings gebied het en sy eie strukture gevra het. Daar behoort dus ook vandag die vryheid te wees om nodige aanpassings te maak.

(c) Funksionele vereistes bepaal die bedieningsvorme

Die kerk het sy basiese funksies. Dit is die voortsetting van hiérdie funksies wat bepalend moet wees by die vasstelling van bedieningsvorme. Om weer na Bolkestein te verwys; Hy sê dat in elke nuwe situasie die deurslaggewende vraag gevra moet word: hoe 
kan ons hier ten beste wees wat ons moet wees, naamlik volk van God, eiendom van Christus, vreemd aan die wêreld, maar tog gerig op die wêreld? Watter vorms die lewe van die gemeente sal moet aanneem, kan nie tevore gesê word nie. In elke nuwe situasie sal weer opnuut daarvoor gesoek moet word. (Tot sover Bolkestein.)

Die beginsel van funksionele ekwivalensie maak vernuwing volstrek moontlik.

\section{Paulus as tentmaker}

Bestaande beginsels gee ons vrymoedigheid om na Paulus se eie praktyk te kyk. Is dit dalk ook 'n vorm wat vandag nuttig mag wees vir die opbou van die kerk?

Sy standpunt en voorbeeld kan ons onder drie punte tuisbring:

(a) Die apostel, en ander wat voluit die evangeliebediening behartig, het 'n reg op onderhoud deur die gemeente. In I Kor 9:7 en 14 stel hy dié beginsel duidelik look in I Tim 5:17-18).

(b) Hyself het bewustelik en beslis van hierdie reg afstand gedoen (I Kor 9:12,15).

Sy normale patroon was om vir sy eie onderhoud te sorg (Hand 18:2-4; Hand 20:33-34; I Tess 2:9). Waarom?

(i) Hy wou nie vir die gemeentes 'n las wees (I Tess 2:9, 2 Tess. $3: 8)$ - soos ander waarmee hy nie geassosieer wou wees nie (2 Kor 11:20).

(ii) Hy wou 'n voorbee/d ste/ wat algemeen geldig is: om nie 'n oorlas te wees nie, maar jou eie sake te behartig en vir die gemeenskap tot voordeel te wees (I Tess 4:11-12; 2 Tess $3: 9 ; 1$ Kor 4:12-16).

(iii) Hy wou twee beginsels tuisbring: "dit is saliger om te gee as om te ontvang" (Hand 20:35), en: 'n bedelaarmentaliteit is verkeerd (2 Tess 3:10).

(iv) Missionêre rede. Alles wat hy gedoen het - en nie gedoen het nie - was gerig om mense te bereik met die evangelie (I Kor 9:22). Om een of ander rede was hy daarvan oortuig dat sy bediening sou skade lei as hy van die algemene reg gebruik sou maak. Daarom is hy so sterk in sy afwysing van gereelde onderhoud. 
(c) Tog het Paulus by geleentheid hulp aanvaar.

Net voordat ons van mening raak dat Paulus hier 'n absolute patroon verkondig het, sien ons dat hyself, ten spyte van sy standpunte hierbo, tog van tyd tot tyd groot waardering uitgespreek het vir hulp wat hy ontvang het. Veral die Filippense het soms gehelp (Lydia se invloed?) (Fil 4:10, 15-16). Maar hy berei ook die Romeine voor dat hy van hulle hulp sou vra (Rom 15:24). Op reis sou hy uiteraard nie maklik vir homself kon sorg nie.

\section{Historiese gesigspunte}

Verskeie historiese studies, soos dié van Ream, ${ }^{81}$ Vischer ${ }^{91}$ en Schillebeeckx ${ }^{101}$ het aangetoon dat die gebruik van ' $n$ "tentmakerbediening" eintlik nooit in die kerkgeskiedenis in onbruik geraak het nie. Dwarsdeur die geskiedenis het die verskillende lyne voortgegaan.

Ook as die ondersoek deur die kontinente van die wêreld gaan, raak dit opvallend dat die tentmakerbediening op baie plekke nie die uitsondering nie, maar die reël is. Trouens, dit was die opvallende voorkoms van hierdie soort bedieningspatroon oral in die Derde Wêreld wat die saak op die ekumeniese agenda geplaas het.

Die International Missionary Council (IMC), wat later die Division of World Mission and Evangelism (DWME) van die Wêreldraad van Kerke (WCC) geword het, het in die vroeë sestigerjare 'n projek geloods oor The Pattern of the Ministry. Na 'n byeenkoms te Arnoldshain in 1962 is ' $n$ verslag gepubliseer genoem $A$ Tent-Making Ministry. ${ }^{11)}$ Dit het eintlik hierdie benaming gepopulariseer. David Paton het die navorsingsprojek in 1965 afgerond met die publikasie van 'n bundel opstelle New Forms of Ministry. ${ }^{12)}$ Hierdie kan amper beskou word as die magna charta van die tentmakerbeweging. Sedertdien het talle boeke en tydskrifte hieroor verskyn en die oë geopen vir die voorkoms van die patroon in alle wêrelddele.

Douglas Webster ${ }^{13)}$ het die kerk in Latyns-Amerika ondersoek en bevind dat baie Kerke aldaar net nooit enige ander patroon as die tentmakerbediening geken het nie. Sundkler se studie oor die bediening in Afrika ${ }^{14)}$ het hom genoop om te sê:

“... most ministers in rural Africa have always been, and are still working on a part-time basis." 14)

So was en is dit ook die geval in Asië ${ }^{15)}$ en die eilande van die Stille Oseaan. ${ }^{161}$

Maar ook in die Weste, dié plek waar die "standaard" patroon van 
voltyds besoldigde leraars ontstaan het, is die tentmaker 'n algemeen voorkomende verskynse| ${ }^{17)}$ - en ook teologiese opleidingsprogramme wat dit vir sulke mense moontlik maak om opleiding te geniet. So maak Winter ${ }^{18)}$ melding van 'n Anglikaanse teologiese skool waarvan die studente onder andere insluit

"bankers, a Hollywood actor, several physicists, and FBI agent, a vice president of a big company, an attorney and an electrical lineman ..."

Die getuienis van tentmakers oral oor is feitlik deur die bank dat dit glad nie maklik is nie, maar dat hulle dit onder omstandighede nie anders sou wou hê nie - deels omdat daar geen ander alternatief is nie, en deels omdat dit moontlikhede bied wat op geen ander manier verwerklik kan word nie.

\section{RIGLYNE EN GEVOLGTREKKINGS}

1. Dit lyk dus asof ' $n$ aantal sake in die oorsigtelike behandeling duidelik geword het.

Eerstens behoort die geskokte reaksie wat so dikwels volg op die kennismaking met die tentmakerpatroon laat vaar word. Dit is ' $n$ (potensieel) legitieme bedieningsvorm met wortels in die Nuwe-Testamentiese kerk en 'n kontinue geskiedenis in groot seksies van die christendom. Dit is trouens slegs in die Westerse kerk, waar die kerk vir groot dele staatsondersteuning geniet het (met ander woorde dié Kerke waaruit die Afrikaanse Gereformeerde Kerke stam) waar die tentmakerpatroon vir 'n tydlank in onbruik verval het.

Tweedens bied die Bybelse gegewens aan vandag se kerk die besliste moontlikheid - ja, die verpligting - om aanpassings in bedieningstrukture te doen op grond van die eise om vandag God se bedoeling in die wêreld voort te sit.

Derdens lyk dit asof die tentmakerbediening hedendaags ' $n$ belangrike bydrae kan lewer om dit vir die kerk moontlik te maak om ' $n$ volwasse en relevante bediening uit te oefen.

2. 'n Aantal belangrike sake moet egter nie uit die oog verloor word nie.

(a) Die persoon van die bedienaar - sy motiewe, gawes en persoonlike omstandighede - sal in die praktyk steeds die deurslaggewende faktor bly. 
lemand wat maar net die beste van twee wêrelde wil hê, sal uiteindelik die kerk 'n onguns aandoen (- maar ook in die voltydse bediening!!.

Die kwalifikasies van 'n persoon en die beskikbaarheid van alternatiewe inkomstebronne sal 'n belangrike woord meespreek. Niemand behoort in ' $n$ tentmakerbediening gedwing te word wat nie daarvoor kans sien nie. Maar niemand behoort verhinder te word as dit wel sy oortuiging is en dit ten beswil van die kerk is nie.

(b) Die meeste van die probleme wat met die idee van tentmakers ondervind word, is die gevolg van 'n oorskakeling van ' $n$ voltydse besoldigde bediening na ' $n$ deeltydse. Die rede is omdat dit nie die organiese groeiwyse is nie, maar meestai noodoplossings is. Die eintlike tentmakerbediening groei nie vanuit voltydse bedienaars nie, maar uit die gemeente self. Die voltydse bediening behoort alleen uit ' $n$ basis van onbetaalde diens op te kom.

(c) Veral Lobinger het in sy verskillende geskrifte uit Suid-Afrikaanse konteks ${ }^{19)}$ duidelik aangetoon dat die deeltydse tentmaker nie verwag moet word om die voltydse persoon te vervang nie. Die hele gemeentelike struktuur moet daarmee saam verander. Dit is slegs 'n goeie ding as dit lei tot ' $n$ meer aktiewe gemeente. Ten slotte is die tentmakerleraar nie ' $n$ (swak) ekwivalent vir die voltydse leraar nie. Wat wel ' $n$ beter alternatief is, is ' $n$ span tentmakers wat met hulle verskeidenheid van gawes ' $n$ korporatiewe bediening uitoefen tot verryking van die gemeente.

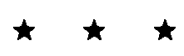

Ekself glo heelhartig in die konsep van die tentmakerbediening. Dit verdien ' $n$ billike beoordeling ook in die Ned. Geref. Kerk.

\section{NOTAS}

1. My eie insigte is breed uitgewerk in ' $n$ Missionére Bediening. Op Weg na strukture vir' $n$ jong kerk, Pretoria 1979. Let ook op die boekelys op bladsye 213-222.

2. Ek gaan nie verder hierdie ig. vorm bespreek nie, maar dit is goed beredeneer en geillustreer deur J. Christy Wilson, Today's tentmakers. Self-support - an alternative model for worldwide witness, Wheaton 1979, 111.

3. "Tentmakerbediening 'moontlik' in NG Kerk", Die Kerkbode 14 Julie 1982, 16.

4. Hier verwys ek graag na Kritzinger, a.w., 147-181. Wat volg, is eintlik maar 'n opsomming en toespitsing van hierdie gedagtes.

5. J.H. Roberts, Die opbou van die kerk volgens die Efese-brief, Groningen 1963, 138. 
6. Onder andere word hier verwys na M.H. Bolkestein. Het gemeentelid, zijn plaats en roeping volgens het Nieuwe Testament, Driebergen 1961; Ronald Fung, Ministry, community and spiritual gifts, Pasadena 1971; A.T. Hanson, Church, sacraments and ministry, London 1975; Hans Küng, Why priests? A proposal for a new church ministry, New York 1972; Edward Schillebeeckx "Creatiewe terugblik als inspiratie voor het ambt in de toekomst", Tijdschrift voor Theologie 19:3 (1979), 266-293.

7. a.w. 35-36.

8. W.G.B. Ream, "The support of the clergy in the first five centuries AD", International Review of Missions vol. 45 (1956), 420-428.

9. Lukas Vischer, "The ministry and a secular occupation", in David M. Paton (ed.), New Forms of Ministry, London 1965, 36-54.

10. Kyk voetnota 6 .

11. "A tent-making ministry. The report to the DWME after a consultation at Arnoldshain on 'The pattern of the ministry'," International Review of Missions, vol. 52 (1963), 47-59.

12. Kyk voetnota 9 .

13. Douglas Webster, Patterns of part-time ministry in some churches in South America, London 1964. Kyk ook Wilfred Scopes (ed.). The christian ministry in Latin America and the Caribbean, Geneva 1962 en die International Review of Missions se Januarie 1977 nommer, vol. 66.

14. Bengt Sundkler, The christian ministry in Africa, London 1960. Kyk ook Norman Goodall \& Eric W. Nielsen, Survey of the training of the ministry in Africa. Part II: Southern Africa, London 1954; Adrian Hastings, Church and mission in modern Africa, New York 1967; en Paul M. Miller, Equipping for ministry in East Africa, Dodoma 1969.

15. Kyk hiervoor o.a. Neil Braun, Laity mobilized. Reflections on church growth in Japan and other lands, Grand Rapids 1971; Lesslie Newbigin, The ministry of the church, ordained and unordained, paid and unpaid, Edinburgh 1953; en James A. Bergquist and P. Kambar Manickam, The crisis of dependency in Third World ministries. A critique of inherited missionary forms in India, Madras 1974.

16. Kyk o.a. Charles W. Forman, "The South Pacific style in the christian ministry", Missiology, vol. 2 (1974), 421-435.

17. Vgl. o.a. Robin Denniston (ed.), Part-time priests?: a discussion. London 1960; James L. Lowery jr., Case histories of tentmakers, Wilton 1976; en John Morris, New ways with the ministry, London 1960.

18. Ralph D. Winter, Theological Education by Extension, Pasadena 1969.

19. Onder andere Fritz Lobinger, "Why we should ordain proven christians", African Ecclesiastical Review vol. 17 (1975), 346-351 en The transformation of the ministry. Report of the ad hoc joint commission for the study of the ministry, Pretoria 1975. 